\title{
CALL in Context: A Brief Historical and Theoretical Perspective
}

\author{
Mustafa Polat \\ Bahcesehir University
}

\begin{abstract}
Computers have been used for language teaching since the 1960s (Warschauer \& Healey, 1998), and several recent studies suggest that there is still a strong need to experiment with technology and digital tools in both education and language learning (Godwin-Jones, 2012; Goertler, 2009; Levy, 2009; Reinhardt \& Ryu, 2013; Zhao, 2003). Because of the speed of technology, there have been drastic changes in every field in which technology is used as a medium. Each time that a society has developed a new medium for the transmission of knowledge, there have been profound consequences for language and language pedagogy (Wright, 2006). In fact, Rankin (2010) admits that the information shift is as drastic as the move from handwritten texts to books from the printing press (as cited in Fargo, 2012). Fargo further points out that information and knowledge are no longer held by the few in select repositories waiting to be disseminated to the masses by a master teacher. Information, both accurate and inaccurate, is free and available for use instantly over the Internet. Due to this and several other innovations and renovations in educational methods, there is a strong need to elaborate on educational technology tools grounded within a historical framework and to reflect on both constraints and affordances of new technologies. Therefore, this article is a partial response to this need; it both draws a map of the current state of computer-assisted language learning (CALL) and positions this map within an existing theoretical and historical view of how technology has been used in education and language pedagogy.
\end{abstract}

Keywords: Computer Assisted Language Acquisition; CALL; L2; pedagogy; educational technology

\section{CALL in Context: A Brief Historical and Theoretical Perspective}

As briefly noted by Warschauer and Healey (1998), computers have been around and used in education and language pedagogy since 1960s. For over forty years, there have been several categorizations to explain how technologies have been used in language teaching and how they have been influenced by or have influenced other Second Language Acquisition (SLA) or educational theories. Some researchers, like Levy (1997), focused selectively on computer assisted language learning (CALL) from the 1960s to the 1990s. This seems practical since every decade from the 1960s onward has identifiable 
characteristics. Warschauer and Healey (1998) divided 30+ years of history from 1960s to 1990s into three phases: behavioristic CALL, communicative CALL, and integrative CALL. In their article, they write, "each stage corresponds to a certain level of technology as well as certain pedagogical approach" (p. 57).

It is also possible to situate the pedagogical use of technology within the framework of different schools of learning. Ally (2008) lists different schools of thought on learning, starting with the behavioristic approach, and then continuing with cognitive psychology and constructivism, and he finally explains a recently proposed theory, connectivism.

Considering all these categorizations, regardless of whether they are based on time, theorists, or schools of thought, what is obvious is the fact that CALL has extensively benefitted from different schools of thought and has developed based on certain technological inventions or innovations achieved in every decade since the first use of computers in language pedagogy. Even today, it is possible to observe how language teaching is influenced by certain pedagogical approaches in the midst of frequently emerging technologies. The discipline has of course come a long way since then, with a combination of education theory and technology being the two interrelated primary drivers of change (Jarvis \& Achilleos, 2013). Therefore, these CALL approaches will be explained in light of each decade of digital innovation and certain schools of learning.

\section{Behavioristic CALL}

First of all, the behaviorist school of thought, influenced by Thorndike (1913), Pavlov (1927), and Skinner (1974), postulates that learning is a change in observable behavior caused by external stimuli in the environment. Behavioristic CALL, conceived in the 1950s and implemented in the 1960s and 1970s, is informed by the behaviorist learning model, and this mode of CALL featured repetitive language drills, referred to as drilland-practice (or, pejoratively, as "drill-and-kill") (Warschauer \& Healey, 1998). Levy (1997), referring to this time frame, thinks that empiricist theory was predominant in language teaching which is described by Stern (1983) as "pedagogically audiolingualism, psychologically behaviorism, linguistically structuralism."

\section{Communicative CALL}

The next stage, communicative CALL, emerged in the late 1970s and early 1980s, at the same time when behavioristic approaches to language teaching were being rejected at both the theoretical and pedagogical level, and when new personal computers were creating greater possibilities for individual work (Warschauer \& Healey, 1998). Warschauer and Healey further state that communicative CALL corresponded to cognitive theories, which stressed that learning was a process of discovery, expression, and development. Cognitive theorists see learning as an internal process, and contend that the amount learned depends on the processing capacity of the learner, the amount of effort expended during the learning process, and the depth of the processing (Ally, 2008). As 
a result, instead of the set of optimal prescriptions for language teaching that was used in the 1950s and 1960s, views became more circumspect reflecting the complexity of language teaching and learning and the attributes and needs of the individual learner (Levy, 1997). Levy (1997) continues by stating that notably new methods began to appear during this period and these rather humanistic methods and techniques engaged the whole person, their emotions and the affective dimension. To illustrate, a few of these methods were Community Language Learning, Total Physical Response and later on, as a far-reaching approach of the time, Communicative Language Teaching. What is really peculiar is that few of these approaches or methods put a deliberate emphasis on teaching with technology during this period although, as stated by Levy (1997). Personal computers such as the Apple II and then Microsoft PCs were introduced then. The most obvious reason for this must be the constraints like accessibility and affordability of these machines, which is still an issue even today for emerging technologies. Regarding what was aimed with computers during this CALL phase, the focus was not so much on what students did with the machine, but rather what they did or were doing with each other while working at the computer (Warschauer \& Healey, 1998).

\section{Integrative CALL}

Although the early 1980s saw a boom in CALL, largely due to the introduction and widespread availability of inexpensive microcomputers, language teacher programmers, and word processing on microcomputers (Levy, 1997). By the later 1980s and early 1990s, critics pointed out that the computer was still being used in an ad hoc and disconnected fashion (Warschauer \& Healey, 1998). Hence, there has been a move towards constructivist theory, claiming that learners interpret the information and the world according to their personal reality, that they learn by observation, processing, and interpretation, and then transform the information into personal knowledge (Ally, 2008). Afterwards, task-based, project-based, and content-based approaches all sought to integrate learners in authentic environments, and also to integrate various skills of language learning and use, which led to a new perspective on technology and language learning, integrative CALL (Warschauer \& Healey, 1998).

\section{Critiques of Three Phases of CALL}

Regarding the above-mentioned three phases of CALL famously identified by Warschauer and Healey (1998), Bax (2003) presents several criticisms against them, and has come up with three new categories, 'restricted, open, and integrated CALL.' Bax claims that Warschauer and Healey's phases are inconsistent in that the nomenclature is misleading. He argues neither behavioristic CALL nor communicative CALL is in accordance with the pillars and boundaries of the behavioristic school of learning and communicative language teaching, respectively. Moreover, he underlines the need for re-evaluating the phases in their dating in addition to nomenclature. 
Based on the revision by Bax (2003), restricted CALL is preferred as an approach rather than a phase, but it is still similar to Warschauer and Healey's behavioristic CALL with the exception of the term itself. Bax's second approach, open CALL, lasted from the 1980s until early $21^{\text {st }}$ century, unlike Warschauer and Healey's communicative CALL. Open CALL approach refers to an era in which it is relatively open in all dimensions-from feedback given to students, to the software types, to the role of the teacher (Bax, 2003). The key characteristic of this approach is the availability of Web and more democratization regarding the use of computers and technology. Unlike Warschauer and Healey (1998), Bax insists that integrated CALL did not yet exist during early 2000s when the article was written (2003). This is quite understandable when it is thought that integrated CALL or integrative CALL requires a thorough integration of computers and technology in education and even further a "normalization" period, which, in Bax's terms (2003), refers to "the stage when a technology is invisible, hardly even recognized as a technology, taken for granted in everyday life" (p. 23). What is worth mentioning here is the fact that the discussion itself and the attempt to understand what CALL has been and currently is are absolutely significant to develop a fully appropriate role for computers in language teaching and learning. Moreover, as Bax (2003) argues, assuming that in general terms we are in an integrated phase of CALL, it is possible that each institution and classroom may also exhibit certain open and even restricted CALL features.

\section{Current State of CALL and Educational Technology}

Currently, there is also a recently proposed theory under discussion (Downes, 2006; Siemens, 2004) which is termed as "connectivism," and it is the integration of principles explored by chaos, network, complexity and self-organization theories. Based on connectivism, which is in the beginning of its development, changing environments, innovations, changes in the discipline and in related disciplines all suggest that learners have to unlearn what they have learned in the past, and learn how to learn and evaluate new information.

In light of the information provided so far in this article, it is obvious that there have been drastic changes since the earliest times of CALL to the present day. These changes have occurred in several diverse but complementary areas: from teachers to learners; needs to aims; media to content; materials to learning environment; and implementation to assessment. Taking these areas into account, there are a few notable things to underline regarding educational technology, CALL, and schools of thought with a focus on learners and teachers:

1. According to Ertmer and Newby (1993), the three schools of thought can, in fact, be used as a taxonomy for learning. Behaviorists' strategies can be used to teach the what (facts); cognitive strategies can be used to teach the how (processes and principles); and constructivist strategies can be used to teach the why (higher-level thinking that promotes personal meaning, and situated and contextual learning). 
2. Strategic use of new educational technologies can enhance learning and teaching. However, to be effective, new educational technologies need to be supported by innovative pedagogical approaches which in turn enable collaboration, communication and mobility (Webster \& Murphy, 2008).

3. The teacher has become a facilitator of learning rather than the font of wisdom, and will find, select, and offer information in a variety of ways on the basis of what the students must learn in order to meet diverse needs (Warschauer \& Healey, 1998).

4. Amidst all this change, issues such as the roles of computers in CALL, other more recent digital tools, optimal approaches to authoring, effects of the technology on the methodology, integration, and evaluation remain central issues, as they have over the last thirty years (Levy, 1997).

5. The era of limited access to desktop computers with a few basic mechanical "drill and kill" software programs is long gone in many contexts. CALL has grown to include online blogs, use of apps, virtual learning environments, computer-mediated communication, among others (Jarvis \& Achilleos, 2013).

6. Although it is difficult to prove Prensky's claim (2001) that today's language learners, as "digital natives," "millennials," "Generation M," or "Net Generation," are completely different from previous generations of 'immigrants,' it is true that our students have changed radically, too. Students can easily retrieve information now (Fargo, 2012). Memorization is less important in this information-rich time (Warschauer \& Healey, 1998) in which the "Google effect on memory" is researched (Sparrow et al., 2011). Therefore with the need to integrate technology meaningfully into language pedagogy, it should also be remembered that good teaching aims to improve students' ability to engage in higher-order thinking; it recognizes the diversity of learners' abilities and needs; and it reflects an awareness of both the complexity of the learning process and the need to make adjustments in different circumstances (VanSlyke, 2003). Learners also need both the technological know-how and the awareness of their own language learning styles/aptitudes to function fully in a multicultural, multilingual world (GodwinJones, 2012). 


\section{References}

Ally, M. (2008). Foundations of educational theory for online learning. In Anderson, T. and Elloumi, F. (eds.) Theory and practice of online learning. Athabasca, AB: Athabasca University. Retrieved from: http://www.tonybates.ca/2008/07/21/ foundations-of-educational-theory-for-online-learning/\#sthash.TGrjFJx8.dpuf

Fargo, J. (2012). Emerging technologies and their application to middle school classrooms. [Web log comment] Retrieved from http://goo.gl/gs5p0w

Godwin-Jones, R. (2012). Emerging technologies. Challenging hegemonies in online learning. Language Learning \& Technology, 16 (2), 4-13. Retrieved from: http:// Ilt.msu.edu/issues/june2012/emerging.pdf

Goertler, S. (2009). Using computer-mediated communication (CMC) in language teaching. Die Unterrichtspraxis/Teaching German, 42(1), 74-84.

Jarvis, H., \& Achilleos, M. (2013). From computer assisted language learning (CALL) to mobile assisted language use (MALU). TESL-EJ: Teaching English as a Second or Foreign Language, 16(4).

Levy, M. (1997). CALL in context I: A historical perspective. In M. Levy. ComputerAssisted Language Learning: Context and Conceptualization (pp. 13-46). Oxford University Press: New York, NY.

Levy, M. (2009). Technologies in use for second language learning. The Modern Language Journal, 93(Supplement), 769-782. doi:10.1111/j.15404781.2009.00972.x

Reinhardt, J. and Ryu, J. (2013). Using social network-mediated bridging activities to develop socio-pragmatic awareness in elementary Korean. International Journal of Computer Assisted Language Learning and Teaching 3(3), 18-33.

Sparrow, B., Liu, J., \& Wegner, D. M. (2011). Google effects on memory: Cognitive consequences of having information at our fingertips. Science, 333(6043), 776778.

VanSlyke, T. (2003). Digital natives, digital immigrants: Some thoughts from the generation gap. The technolog17y source, $7(3)$.

Warschauer, M., \& Healey, D. (1998). Computers and language learning: An overview. Language Teaching, 31(02), 57-71.

Webster, L and Murphy, D. (2008). Enhancing learning through technology: challenges and responses. In Kwan, R., Fox, R., Chan F.T. \& Tsang, P (Eds). Enhancing learning through technology: research on emerging technologies and pedagogies (pp. 1-16). New Jersey: World Scientific. 
Wright, S. (2006). Language and the internet. Sociolinguistica, 20(20), 166-182.

Zhao, Y. (2003). Recent developments in technology and language learning: A literature review and meta-analysis. CALICO Journal, 21(1), 7-27. 